\title{
E-commerce Supply Chain Routine Evolution and Dynamic Capability Formation Mechanism of Integrating Situational Knowledge
}

\author{
Wang Shuyi \\ Zhejiang Gongshang University \\ College of Business Administration \\ Hangzhou, China \\ 793938624@qq.com, Scarlettwsy@126.com
}

\author{
Xu Jianwei \\ Zhejiang Gongshang University \\ College of Business Administration \\ Hangzhou, China \\ pwa2002@163.com
}

\begin{abstract}
The dynamic capability of e-commerce supply chain determines the competitiveness of e-commerce to a large extent, and it is the key for enterprises to gain competitive advantages. However, there is a lack of relevant research on the dynamic capabilities of e-commerce supply chain. This paper takes the dynamic capability of e-commerce supply chain as the research object, analyzes the situational characteristics of e-commerce supply chain using context perception theory and convention theory, discusses the formation mechanism of e-commerce supply chain service practice, and proposes the dynamic capability of e-commerce supply chain. The conceptual model and basic structure provide a new perspective for carrying out "conventional" research and capacity mechanism research in a complex environment.
\end{abstract}

Keywords-Situational knowledge; Routine; E-commerce supply chain; Dynamic capacity

\section{INTRODUCTION}

Compared with traditional supply chain, e-commerce supply chain has very typical situational characteristics — the complexity of the task structure, the highly uncertain environment, the urgency of response time, and the fierce competition. The special situation of the e-commerce supply chain requires adaptability to meet the customer's established needs and to coping with environmental changes and innovative capabilities to provide customers with added value [1]. However, these two dynamic capabilities and can not be easily obtained. Zollo and Winter (1999) argued that "dynamic capabilities are a collective learning method through which companies can systematically generate and modify their business routines, thereby improving the efficiency of the company"[2]. Eisenhardt and Martin (2000) pointed out that "dynamic capabilities should be a strategic routine to adapt to changes in the environment by continuously updating resource allocations" [3]. Zollo and Winter (1999) believe that "there are operational routines within the organization to deal with the various daily operations in the organization's operations and improve the organization's operational efficiency" [2]. Due to the complexity of the task structure, the highly uncertain environment, the urgency of response time, and the fierce competition, the e-commerce supply chain needs to sense its environment quickly and accurately and make a corresponding response.

\section{EVOLUTION OF THE ROUTINE OF INCORPORATING SITUATIONAL KNOWLEDGE}

Compared with the vertical structure of the traditional supply chain, the e-commerce supply chain is a network structure centered on e-commerce platforms (or core enterprises), which includes a large number of entities such as customers, suppliers, e-commerce platforms and logistics providers. The development of information technology and economy, the continuous improvement of the human physical and spiritual needs have bring great changes to the e-commerce supply chain_-The environment changes more quickly and frequently, the task structure is more complex, the customer needs are more varied, the time requirements for logistics are higher, and the competition is more intense. Therefore, the situation of e-commerce supply chain is more complex. According to the characteristics of e-commerce supply chain and combining with other scholars' research, the e-commerce supply chain situation is divided into demand situation, resource situation, logistics situation and relationship situation [4-5]. The connotation is shown in Table 1. 


\begin{tabular}{|c|c|}
\hline Type & Situational Connotation \\
\hline Demand situation & $\begin{array}{c}\text { The customer's preferences in terms of product specifications, quantity, price, quality and } \\
\text { delivery time. }\end{array}$ \\
\hline Resource situation & $\begin{array}{c}\text { The resources needed to complete customized products, such as production resources, technical } \\
\text { resources, outsourcing resources. }\end{array}$ \\
\hline Logistics situation & $\begin{array}{l}\text { The logistics processes that must be experienced to complete a customized product, such as } \\
\text { warehousing and distribution. }\end{array}$ \\
\hline $\begin{array}{l}\text { Relationship } \\
\text { situation }\end{array}$ & Relationship with suppliers, distributors, and outsourcers. \\
\hline
\end{tabular}

According to the connotation of the situation of e-commerce supply chain and the characteristics of the e-commerce supply chain and combined with existing research [6],we define the e-commerce supply chain situational knowledge as silent knowledge which is formed by sensing the complex internal and external environments during the operation process and helps improve organizational operating efficiency[7-8]. Divide the situational knowledge into two categories: situational knowledge I and situational knowledge II. The situational knowledge $\mathrm{I}$ is the basic knowledge aggregates in the e-commerce supply chain which often manifests in certain rules, specific content such as standards

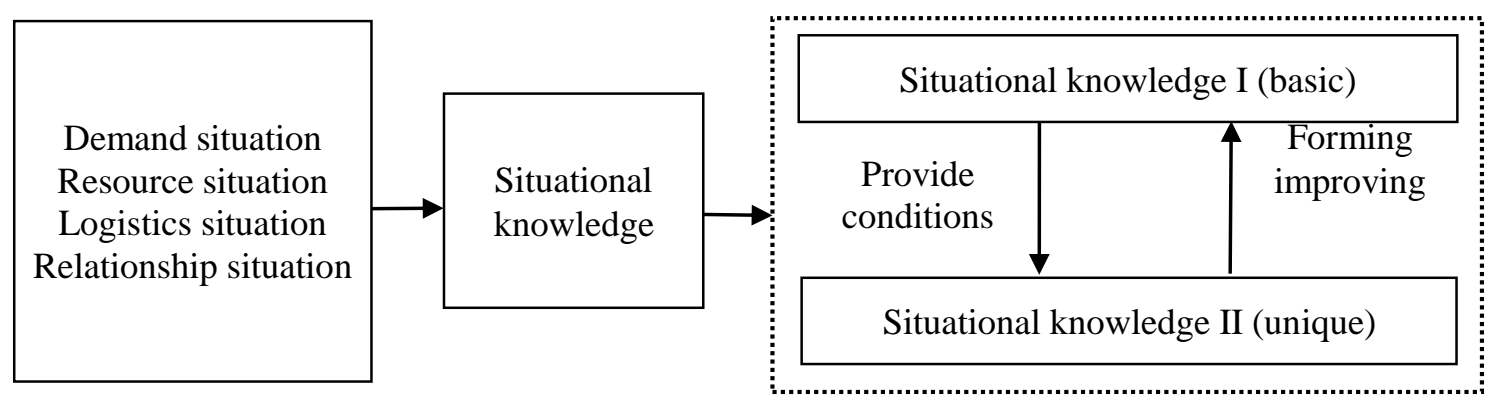

Fig. 1 Classification and relationship of situational knowledge in e-commerce supply chain

Stene (1940) first introduced routine into organization management, and considered that "routine is the key factor for an organization to achieve its goals successfully". In 1982, Nelson and winter's introduced biological evolution theory into the study of routine for the first time in their book [9], and pointed out that routine is the core concept of evolutionary economics theory. It is the "gene" of tissue and constitutes the genetic factor of evolution theory. Zollo and Wintern (2003) believed that "routinen is a stable pattern of behavior that describes the organization's response to internal and external environmental changes, stimuli, etc" [4]. Cohendet and Lierenaan (2003) argued that "routine is a way to learn why to do (motivation and motivation) and how to do (cognition and synergy) in 'doing'"[10]. Hodgson and Knudsen (2004) considered "routine to be a form of organization that is used for individual teams to behave under certain conditions". Through the study of the routine, it is found that (1) The organization will form a large number of routines in the long-term production and operation process; (2) The routine is one stable aggregates of knowledge, rules; (3) The routine and procedures, and it is an important basis for guiding the e-commerce supply chain to perform stable daily business activities. It provides a good environment for the formation of situational knowledge II; situational knowledge II is an aggregates of unique knowledge in the e-commerce supply chain which responds to environmental changes by facilitating and improving situational knowledge I. It is the source of differentiated competitiveness in the e-commerce supply chain and characterized by learning, dynamic and intangibility [9]. Figure 1. does not occur at the very beginning, but only after experiencing internal and external stimuli; (4) The routine will evolve. Based on the characteristics above, we considers that e-commerce supply chain routine are stable knowledge aggregates with self-renewal capabilities after they have formed and experienced selection processes. This kind of knowledge aggregate can be expressed as a specific procurement approach, production method, distribution process, and reverse logistics program based on an e-commerce platform. And it also can be expressed as intangible organizational culture, efficient learning model, and rapid feedback mechanism that result from the collaboration of various node companies. We divide e-commerce supply chain routines into routine I and routine II. The relationship between sotuational knowledge and e-commerce supply chain routine is shown in Figure 2. 


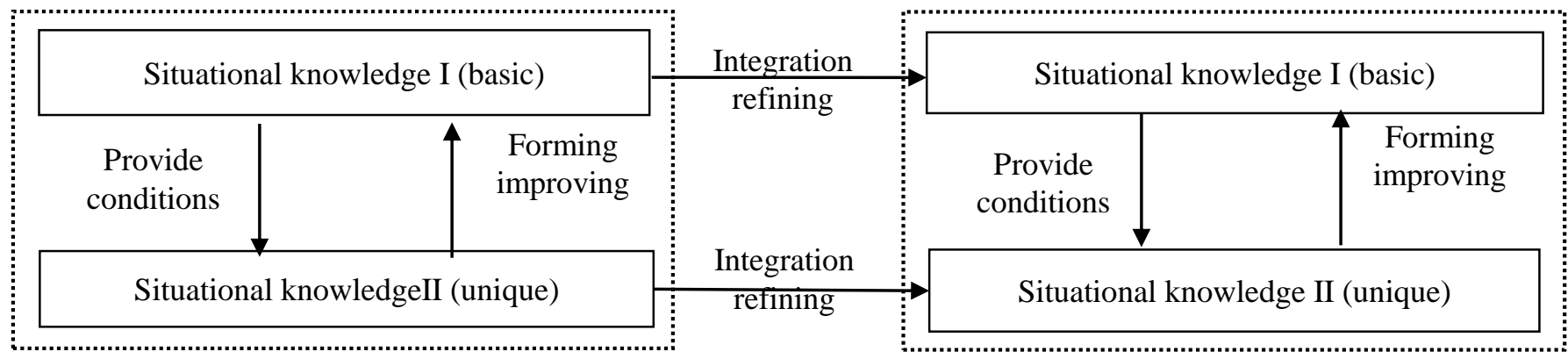

Fig. 2 Relationship between situationual knowledge and e-commerce supply chain routines

We draws on Nelson and Winter's (1982) evolutionary point of view in economics [9] and reinforcement theory in organizational behavior, and believes that e-commerce supply chain routines are driven by internal factors and the external environment. The evolution mechanism of e-commerce supply chain routines is shown in Figure 3.

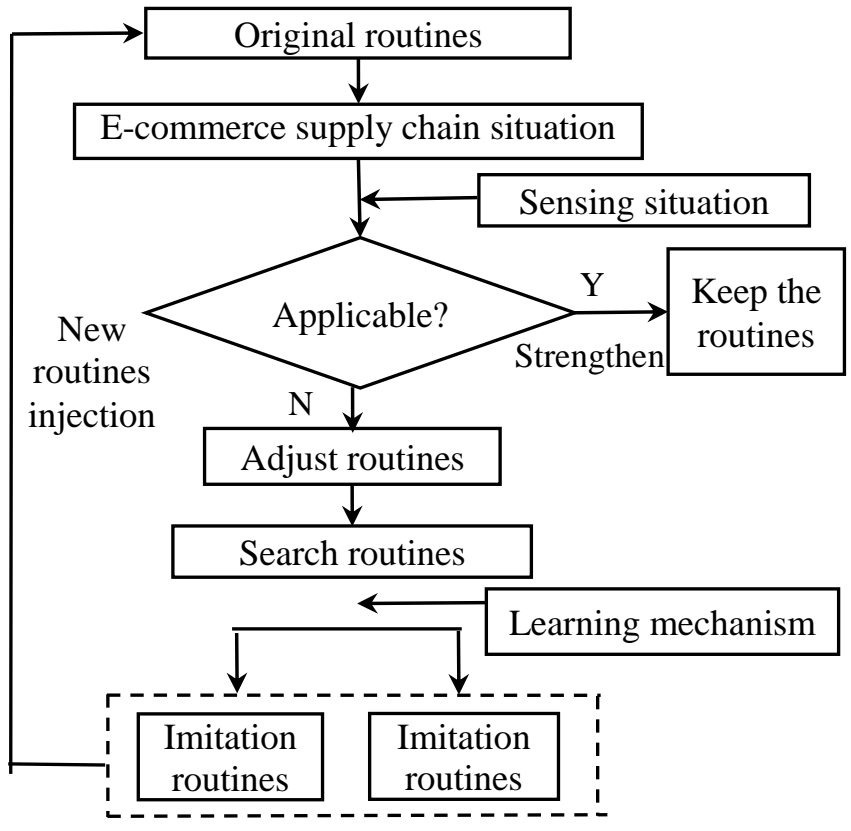

Fig. 3 Routineal Evolution Model

E-commerce supply chain routines are divided into original routines, imitation routines, and innovation routines. The original routine is an effective routine for e-commerce supply chain which is stabilized, and is an organic combination of routine I and routine II. After analyzing and identifying situations in actual operations, if existing routines are still valid, the original routines will be sustained and reinforced. Over time, if the environment is stable, this part of the reinforced knowledge will be further integrated and refined into the routine in the supply chain, and will be retained. However, the rapid economic development has made it difficult for all walks of life to have a stable internal and external environment. Therefore, in the actual operation of the e-commerce supply chain, many existing knowledge or routines will gradually lag behind and lose their proper function. When the original rules, procedures, and standardization workflows may not meet actual needs, they will exert their subjective initiative to start exploring and acquiring new knowledge based on the original routines and apply it in routine to test its feasibility. In the specific implementation process, the original knowledge or routine will undergo "reorganization" or "mutation" to generate new knowledge and routines. In this process new knowledge and routines are formed, each node company in the e-commerce supply chain will virtually adopt the higher-level routines (the routine II with learning nature) to guide this learning and searching process. At the same time, the real part of these new knowledge and new routines will be absorbed and used by each node company in the chain.

\section{EVOLUTION OF E-COMMERCE SUPPLY CHAIN DYNAMIC CAPABILITIES BASED ON CUSTOMARY EVOLUTION}

Many scholars who study dynamic capabilities think that the evolution of routines is the process of formation of organizational dynamic capabilities. The e-commerce supply chain dynamic capability is a learning activity driven by internal and external environment and helps achieve the highest degree of satisfaction with lower operating costs through e-commerce platform. Through this learning mechanism, the e-commerce supply chain could systematically generate and modify its operating procedures to improve efficiency. The dynamic service capability of e-commerce supply chain consists of four aspects: perception ability, operational ability, coordination ability and learning ability, and its essence is the process of e-commerce supply chain updating and evolving continuously.

Perception ability is the most basic ability in the dynamic capabilities of the e-commerce supply chain, evolved from the routine I. Operational ability evolves from routine I and is quite necessary, including structural design routine, cognitive management routine, and relationship management routine. The service objects of the e-commerce supply chain are mostly "end-customers". Due to the individualization and diversification of customer needs and the urgency of response time, services that satisfy customers' flexible needs and agility requirements have become an important factor driving the supply chain's operational abilities. Supply chain operational ability is generally based on alliances. In addition to emphasizing the ability of each node to operate independently, it also emphasizes cooperation to enhance collaboration 
efficiency and reduce operating costs. E-commerce supply chain coordination ability refers to the organic aggregates of routine II used to coordinate the business activities of each node and to achieve the e-commerce supply chain goals. E-commerce supply chain learning ability belongs to the second-order capability (innovation capability) proposed by Winter (2003) [4], which is a kind of improvement of perception, operation, and coordination ability through the process of knowledge search, knowledge coding, knowledge sharing, and knowledge internalization. It is one kind of innovation ability, also one kind of integration ability, evolved from routine II and is very important. The e-commerce supply chain service capability formation mechanism is shown in Figure 4.

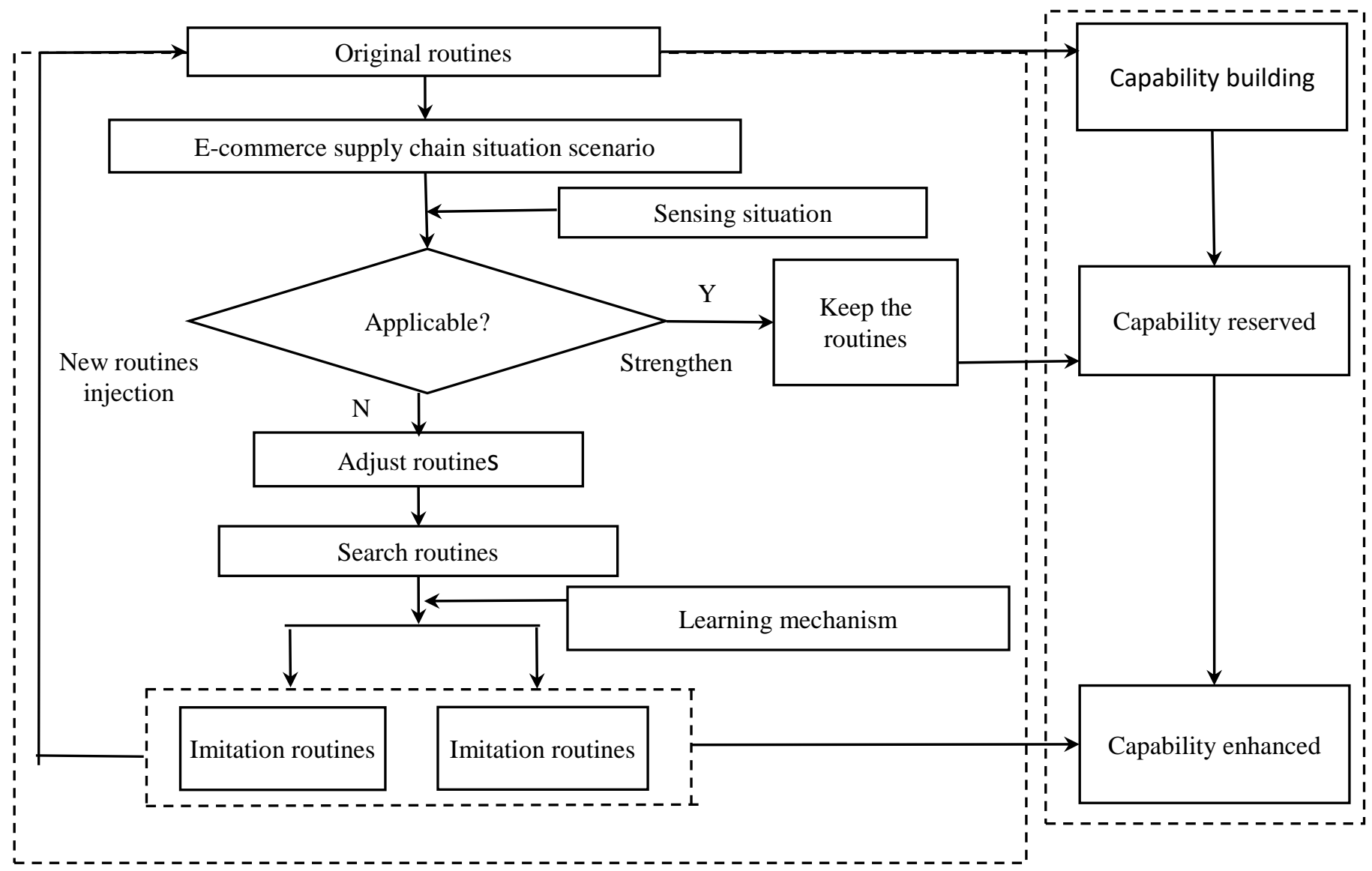

Fig. 4 Evolutionary Mechanism of Routine Capability and E-commerce Supply Chain Dynamic Capabilities

\section{CONCLUSION}

This paper studies the mechanism of situation knowledge, routine evolution and dynamic capability formation of e-commerce supply chain. It considers that there are five situation faced by e-commerce supply chain: demand situation, resource situation, logistics situation and relationship situation, among which demand situation is the most important situation factor in the four situations. The concept of situational knowledge is put forward and divided into two categories: situational knowledge I and situational knowledge II. Situational knowledge I provides a better environment for the formation of situational knowledge II, and situational knowledge II has a promoting effect on the acquisition of situational knowledge I. The supply chain routine is an organic collective of knowledge, which is obtained through the integration and refinement of situational knowledge and can be divided into supply chain routine I and supply chain routine II. Two types of situational knowledge and two types of routines are refined, strengthened, reorganized, and mutated according to a certain law and then the E-commerce supply chain routines are formed. The dynamic capability of e-commerce supply chain consists of four aspects: perception ability, operational ability, coordination ability and learning ability, and its essence is the process of e-commerce supply chain updating and evolving continuously, perception ability and learning ability occupy more important positions. In the 
process of building these four aspects, each node company in the chain should pay special attention to these two aspects.

\section{ACKNOWLEDGMENT}

The paper was fully supported by MOE (Ministry of Education in China) Project of Humanities and Social Sciences (Project No.12YJA630160).

\section{REFERENCES}

[1] Wang C L, and Ahmed, P K.Dynamic capabilities: A review and research agenda [J]. International Journal of Management Reviews, 2007, 9(1):31-51.

[2] Zollo, M. \&Winter, S.G. Form organizational routines to dynamic capabilities, A working paper of the Reginald $\mathrm{H}[\mathrm{M}]$. Jones Center, the Wharton school University of Pennsylvania.1999.

[3] Eisenhardt, K M, and Martin, J A. Dynamic capabilities: What are they? [J]. Strategic Management Journal, 2000, 21(21); 1105-1121.

[4] Winter, S G. Understanding dynamic capabilities [J]. Strategic Management Journal, 2003.24 (10):991-995.

[5] Robert A. Paton, Stephen McLaughlin .Services innovation: Knowledge transfer and the supply chain [J]. European Management Journal, Volume 26, Issue 2, April 2008, Pages 77-83.

[6] Patrick Cohendet, Patrick Llerena. Routines and incentives: the role of communities in the firm [J]. Industrial and Corporate Change, 2003, 12(2):271-297.

[7] Geoffrey M Hodgson, Thorbjørn Knudsen. The firm as an interactor: firms as vehicles for habits and routines. Journal of Evolutionary Economics, 2004, 14(3)281-307.

[8] Nelson, Winter. Evolutionary Theory of Economic change [M]. Cambridge: Hazard University Press, 1982:45-62.

[9] Swafford P M, Ghosh S, Murthy N. The antecedents of supply chain agility of a firm: Scale development and model testing [J]. Journal of Operations Management. 2006, 24(2): 170-188.

[10] Teece D, J Pisano, G Shuen. Dynamic capabilities and strategic management [J]. Strategic Management Journal, 1997 (18): 509-533. 